\title{
“EL REgRESO ES LA RAZÓN DE NUESTRA PARTIDA". PERCEPCIONES CAMBIANTES SOBRE EL RETORNO EN LA EXPERIENCIA DE POBLACIÓN MIGRANTE EN EL ESTADO DE MÉXICO
}

\author{
“RETURN IS THE REASON OF OUR Migration". \\ Changing Perceptions about Return in the Experience \\ of Migrants in the Estado de Mexico
}

\author{
Ana Elizabeth Jardón Hernández* \\ doi: https://doi.org/10.31644/ED.V9.N1.2022.A08
}

\begin{abstract}
Resumen: El estudio de la migración de retorno de mexicanos en Estados Unidos ha cobrado mayor importancia a partir de la crisis económica internacional de 2008. Si bien son diversas las aproximaciones teóricas que lo explican, en este trabajo se reflexiona sobre la propuesta conceptual de las "movilidades del retorno" para comprender la complejidad de este proceso, así como los sentidos que adquiere entre sujetos migrantes que hacen parte de la dialéctica entre el “aquí en el allá” y el "allá en el aquî". A partir de una metodología cualitativa se exponen tres casos que explican el constante reposicionamiento del retorno ante las circunstancias, particularidades y contextos en los que se ven inmersos estos sujetos migrantes originarios del Estado de México y/o establecidos en el mismo, cuyas experiencias se entrelazan en varias expresiones que van de lo real a lo virtual, hasta lo imaginado, deseado, forzado y/o negado.
\end{abstract}

Palabras clave: movilidades del retorno, imaginarios sobre los proyectos de migración y retorno, retorno como aspiración, Estados Unidos-México.

Abstract: The study of return migration from Mexicans at the United States has become more important since the international economic crisis of 2008. Different theoretical approches explain return, nevertheless, this article ponders on the conceptual proposal of the "mobilities of return" to explain and better understand the complexity of the process, as well as its meanings for

\footnotetext{
* Dra. en Ciencias Sociales, profesora investigadora Centro de Investigación en Ciencias Sociales y Humanidades, Universidad Autónoma del Estado de México, México. ORCiD: https://orcid.org/0000-0002-8983-1809. Correo-e: ileana.14@hotmail.com.
}

Fecha de recepción: 03/05/2021. Fecha de aceptación: 03/09/2021. Fecha de publicación: 31/01/2022.

\section{(cc) BY-NC-ND}

EntreDiversidades. Revista de Ciencias Sociales y Humanidades, Vol. 9, Núm. 1 (18), enero-junio 2022. Páginas: 200-222 ISSN-e: 2007-7610. https://doi.org/10.31644/ED.V9.N1.2022.A08 
migrants living the dialectic process of being "here in there" and there in here". Using qualitative methodology, three cases are presented to explain return as a constantly repositioning project under the circumstances, particularities, and the contexts that Mexican migrant people are facing. Their expressions shift between the real, imaginary, virtual, desired, forced and denied.

Keywords: return mobilities, imaginaries on proyects of migration and return, return as an aspiration, United States-Mexico.

\section{Introducción}

¿Por qué?, ¿para qué?, ¿cómo?, ¿cuándo partir? y ¿cuándo volver? entremezcla un conjunto de respuestas que dan inicio, configuran y reconfiguran los proyectos y trayectorias migratorias. Pensar en volver antes de partir, pero también recrear los imaginarios sobre el retorno durante el tránsito, la estancia en otro país y el retorno mismo asigna a la migración un carácter procesual que permite entender las percepciones, las representaciones y los sentidos que las personas otorgan a los retornos en y durante la experiencia migratoria.

La expresión “[...] todos mis piensos son volver pa'tras", tomada de la narrativa de un sujeto migrante originario de Michoacán, lleva a reflexionar sobre "el ansia de retorno entre los migrantes [...] de encontrarse en su lugar de origen, la obsesión, casi desesperación por el retorno [...] y energía dirigida a un objetivo concreto irremplazable: volver" (Durand, 1996: 9). Esta añoranza y deseo por regresar se reconoce también entre la población migrante de otras latitudes y otros tiempos que, aunque con diferentes trayectos y cruces de fronteras, tampoco desdibuja las intenciones de retornar, como ocurre por ejemplo entre la población senegalese en Italia, cuyo discurso en algunos casos deja entrever que "el regreso es la razón de su partida" (Sinatti, 2011).

$\mathrm{Al}$ respecto, Cassain (2019) establece que "los retornos se hacen", pues la comprensión de estos como un proceso posibilita su emergencia y desarrollo en múltiples momentos y lugares:

[...] en la fase de la emigración, cuando el retorno adquiere distintos sentidos en el proyecto migratorio antes de partir; en la fase de la inmigración, cuando esa idea acerca del retorno [...] [o no retorno] se va transformando y se experimentan movilidades de retorno múltiples; hasta en la fase específica de la "migración de retorno", cuando después de tomar la decisión de "reestablecerse" en el lugar de partida con algún viso de permanencia, o bien, de transitar a una nueva experiencia, que no necesariamente supondrá el "cierre" de la trayectoria migratoria (2019: 155).

En tal sentido, el objetivo de este trabajo es analizar las (re)configuraciones que el retorno adquiere en los proyectos y trayectorias migratorias de la población mexiquense con experiencia migratoria internacional, específicamente en Estados Unidos. Los casos que se exploran corresponden a población de los municipios de Coatepec Harinas, Ixtapan de la Sal y Nezahualcóyotl del Estado de México. A partir de una metodología cualitativa y un enfoque biográfico recupero la voz y subjetividad de las y los informantes sobre las expresiones de un retorno que se piensa, se planifica,

EntreDiversidades. Revista de Ciencias Sociales y Humanidades, Vol. 9, Núm. 1 (18), enero-junio 2022. Páginas: 200-222 ISSN-e: 2007-7610. https://doi.org/10.31644/ED.V9.N1.2022.A08 
ocurre y/o se queda en los imaginarios de estos migrantes que tomaron la decisión de partir, probablemente pensando en volver; que están en Estados Unidos con la idea constante de retornar a México y/o que se encuentran de regreso en México con intenciones de re-emigrar a ese país.

Para tal efecto, en la primera parte de este trabajo se sitúa la comprensión del retorno en el marco explicativo de las "movilidades del retorno" — concepto propuesto por King y Christou (2011) — con la finalidad de exponer que el retorno puede tomar formas diversas, que pueden ser más o menos permanentes (Sinatti, 2011), así como de incluir las muchas expresiones que este puede adquirir cuando entre la intención y/o la concreción del mismo se entrelazan elementos reales, virtuales, imaginados, deseados, forzados o negados.

En el segundo y tercer apartado se expone la metodología que sustenta el desarrollo de este trabajo, las técnicas de recolección y análisis de la información, además de presentarse una breve descripción sobre las causas del retorno de la población de origen mexiquense. Posteriormente, se realiza un acercamiento a las narrativas de los sujetos migrantes entrevistados con la finalidad de vislumbrar los posicionamientos, reconfiguraciones y expresiones que el retorno adquiere entre la población mexiquense y que hace parte de las llamadas movilidades del retorno. Para ello, se exponen tres casos que, por un lado, sustentan la noción de la migración como un proceso que no necesariamente concluye con el retorno (Cassarino, 2004) y, por otro, muestran la constitución de un retorno que se interpreta y reinterpreta según el pasado, el presente y las expectativas del futuro (Hirai y Sandoval, 2016). Proceso que según los lugares y los momentos adquiere sentidos diversos: yéndose, pero volviendo, quedándose, pero volviendo, volviendo, pero yéndose $y$, en definitiva, vivir migrando. Por último, se presentan las conclusiones y reflexiones de este trabajo.

\section{Movilidades del retorno: marco explicativo para su comprensión}

En los estudios sobre migración de retorno se ha avanzado en la reflexión teórica-conceptual de dicho proceso así como en el análisis de su asociación, no siempre crítica, con otras formas de movilidad que se relacionan o dan cuenta de un regreso en respuesta a circunstancias y motivos tan diversos como lo son las características de quienes están retornando y de sus grupos familiares y comunitarios, así como los territorios a los que regresan y los tiempos en los que lo hacen.

A modo de ejemplo, Long y Oxfeld (2004, citados en King y Christou, 2011: 452) proponen distinguir entre migración de retorno y retorno. La primera acepción se refiere al desplazamiento físico que se realiza con el fin de permanecer temporal o permanente en el lugar de origen, mientras que el segundo se trata de un concepto más amplio que incluye migración de retorno y repatriación, así como los retornos provisionales, temporales y los imaginados. Esto último implica el reconocimiento de un retorno que puede ocurrir en diferentes temporalidades y por diversos motivos, así como de aquel que se queda en el plano de lo imaginario, del "terruño que la gente describe en su mente, la imagen del lugar de origen construida a partir de memorias e imaginación” (Hirai, 2012: 97), pero que no siempre se materializa, por lo que se queda a nivel de intención y de motivación (Parella, et al., 2019).

Además de lo anterior, el denominado dilema del retorno —en el caso de la migración México-Estados Unidos - ha permitido demostrar que la complejidad asociada con la decisión

EntreDiversidades. Revista de Ciencias Sociales y Humanidades, Vol. 9, Núm. 1 (18), enero-junio 2022. Páginas: 200-222 ISSN-e: 2007-7610. https://doi.org/10.31644/ED.V9.N1.2022.A08 
de permanecer en ese país o regresar a la comunidad de origen se expresa en un sentido de vida, donde migrar es moverse continuamente. Vivir migrando hace que la decisión de retornar esté envuelta de dilemas e incertidumbres (Anguiano, 2000: 166), como ocurre en el caso de Ana María y Quico Correa, una familia de Los Altos de Jalisco, en el que Espinosa (1998) explora el debate entre el establecimiento a la mexicana en Estados Unidos y el retorno como un mito, una ilusión o una ideología.

Repensar el concepto ha permitido avanzar en la comprensión del retorno como un proceso que no se agota en un ciclo migratorio, es decir, en un viaje de ida que concluye con la vuelta. Por el contrario, se ha puesto de manifiesto que el retorno puede ser el comienzo de otras movilidades, por lo que no necesariamente representa el fin del proyecto migratorio (Guarnizo, 1997; Parella, et al., 2019). Visto así, la idea de un ciclo migratorio que inicia con la migración, se desarrolla con la inmigración y concluye con el retorno difícilmente se sostiene en la era de la globalización (Hirai, 2013: 103), donde la circulación de personas, objetos, dinero, información y símbolos pone de manifiesto, en algunos casos, que las personas migrantes no viven ni permanecen en el mismo lugar, sino que "residen en el viaje" (2013: 103) y se encuentran en constante movimiento.

En torno a ello King y Christou (2011: 453) proponen el concepto "movilidades del retorno", con el propósito de describir y reflexionar estos desplazamientos desde el punto de vista de sus agentes (perspectiva emic) —en lugar de privilegiar los problemas de definición y medición-. Para ello, centran su planteamiento en la llamada "ontología del retorno", con el fin de comprender y analizar el retorno entre sujetos migrantes que consideran regresar en algún momento a su "hogar" o "patria", con la que tienen vínculos históricos y emocionales. Hablar de movilidades del retorno supone entonces una elasticidad o flexibilidad del concepto, pues extiende su significado a través del tiempo, del espacio y de las generaciones. Así, el lugar del retorno y el tipo de movimiento puede tener y entrelazar varias expresiones que van de lo real a lo virtual, lo imaginado, lo deseado, lo forzado y/o lo negado.

Esta noción implica además que los productos del regreso — quizá imaginados o planificadosno sean siempre los esperados, así un retorno que se pensó temporal puede terminar siendo permanente, o viceversa. En este punto, es posible situar la propuesta de Cassain (2019: 243) sobre "las formas de gestionar la relación con lo incierto antes de partir, pues según sea el caso, el retorno evocará relaciones con lo im/previsto, im/pensable, im/probable e im/posible". Desde esta postura, la autora advierte entonces que las experiencias de migración y las percepciones sobre el retorno pueden ser y serán transformadas según las posiciones en las que se encuentran los sujetos migrantes en determinado momento y lugar de sus trayectorias. Es decir, en el retorno, sus sentidos y reinterpretaciones hacen parte de un "proceso subjetivo largo y complejo en el que se entremezclan recursos, emociones, oportunidades y decisiones" (Hirai y Sandoval, 2016: 278).

Siguiendo con la propuesta de King y Christou (2011), la diversidad que expresan las movilidades asociadas con el retorno puede leerse desde tres paradigmas o enfoques — movilidad, transnacionalismo y estudios de la diáspora-, de los cuales me centraré en dos de ellos. En primer lugar, el paradigma de la movilidad se traduce en un conjunto de movilidades interdependientes - corporal, material, imaginada, virtual y comunicativa - que corresponden también con las

EntreDiversidades. Revista de Ciencias Sociales y Humanidades, Vol. 9, Núm. 1 (18), enero-junio 2022. Páginas: 200-222 ISSN-e: 2007-7610. https://doi.org/10.31644/ED.V9.N1.2022.A08 
expresiones y sentidos que el retorno puede tener. Desde este paradigma se cuestiona la naturaleza estática de la sociedad y en su lugar se expresa el movimiento, el cambio y la falta de lugar. Esto significa que al retorno le acompaña una tensión entre la movilidad y la búsqueda por establecerse, reincorporarse, pertenecer y volver a un hogar que ya no necesariamente es el que era debido a las reconfiguraciones que han experimentado los lugares y las personas (Hannam, Sheller y Urry, 2006: 10).

Por ello, desde este paradigma se cuestiona también la naturaleza del retorno, de aquel que no necesariamente ocurre en un escenario estático, por lo que implica cuestionarse retornar a dónde, a qué y con quién. Así, son, en parte, estos planteamientos los que despiertan las muchas emociones que el retorno puede tener entre las personas migrantes: esperanza, desesperación, sufrimiento, inquietud, angustia o hasta una falta de adaptación que los lleva a sentirse como extraños; la expresión "mojado en mi propia tierra” permite hablar, según Martínez (2019), de la frustración, la tristeza y el enojo que se experimenta con un retorno que ocurre después de haber estado varios años fuera de México. Así, una mezcla de expresiones entre lo real, lo imaginado y lo deseado pueden hacer que el retorno corporal propicie una experiencia muy diferente a la vivida en ese lugar antes de emigrar, es decir, al espacio y el tiempo que se mantuvo en el imaginario de las personas migrantes (Cassain, 2019) ante la "idealización del pasado, el terruño y lo propio" (Hirai, 2012: 97).

"Llegas allí y las cosas no son iguales", establece Maitilasso (2017: 127) a partir de la narrativa de uno de sus entrevistados, ${ }^{1}$ lo que le permite dar cuenta de la mezcla entre el deseo de regresar y el temor a sentirse un extraño en su propio hogar. El retorno es entonces un proceso complejo que difícilmente se resume en un mero regreso a la condición previa a la salida. De acuerdo con Schutz (1974, citado en Piñeiro y Ferrer, 2015: 174), con el retorno la persona migrante se enfrenta a un "doble desarraigo: extraño en el lugar de destino, verifica con dolor a su regreso al hogar que nadie es profeta en su tierra y que retornar viene a significar, a fin de cuentas, emigrar dos veces".

Los planteamientos de estos autores tienen una estrecha relación con la noción del tiempo. Sayad (2010: 266-267) señala que este es para la población migrante de retorno una vuelta al momento anterior a la inmigración, una retrospectiva hacia los recuerdos de la memoria. Por tanto, plantea el autor, "[...] no puede existir un verdadero retorno, un retorno a lo idéntico, porque, aunque el espacio permita las idas y vueltas, no se puede volver al tiempo de partida, volver a ser tal como éramos en el momento de la partida, ni tampoco reencontrar, tal y como los dejamos, los lugares y las personas" (1998: 267). Así, el acto de retornar viene acompañado de diversas emociones, decepciones y sufrimientos al volver y no encontrar las cosas tal y como se las dejó o como se las imagina.

Una segunda propuesta teórica para comprender las movilidades del retorno se asocia con el retorno recurrente, visto como una práctica que hace parte de la vida de las y los migrantes transnacionales, "que viven en un territorio extendido, con una doble dialéctica: allá en el aquí - aquí en el allá” (Sassone, 1988: 83). Esta noción también abordada por Sayad (2010: 269)

\footnotetext{
${ }^{1}$ En este estudio se explora la movilidad geográfica de personas malienses residentes en España, un colectivo que cobró mayor presencia entre 2000 y 2010 (Maitilasso, 2017).
}

EntreDiversidades. Revista de Ciencias Sociales y Humanidades, Vol. 9, Núm. 1 (18), enero-junio 2022. Páginas: 200-222 ISSN-e: 2007-7610. https://doi.org/10.31644/ED.V9.N1.2022.A08 
—aunque no propiamente desde el transnacionalismo, sino para la interpretación de las ausencias y presencias que acompañan al acto de emigrar - permite establecer que los sujetos que retornan son "hombres del entredós, entre dos lugares, entre dos tiempos, entre dos sociedades, entre dos modos de estar o de entre dos culturas". Esta liminalidad de la experiencia migrante es la que según Bhabha (2002 [1994]: 269) es parte de la supervivencia del migrante, ya que supone encontrarse en medio (in between) de dos condiciones, ni en un lado, ni en el otro, con la conciencia de ser de aquí y de allá (Piñeiro y Ferrer, 2015).

Al mismo tiempo, se constituye en una de las paradojas de la inmigración: "ausente ahí donde está presente, y presente allí donde está ausente. Doblemente presente y doblemente ausente: presente en el país de inmigración y ficticiamente en el de origen, pero también ausente de modo ficticio en el país de inmigración y efectivamente en el país de origen” (Sayad, 2010: 270). Se trata entonces de "presencias imaginadas" que se alimentan, se sostienen y se facilitan con el constante uso de la tecnología, que sin importar la distancia permiten contrarrestar la ausencia física (Goycoechea y Ramírez, 2002: 43). Así, los imaginarios migratorios — donde lugares y tiempos relacionados por la persona migrante se representan en emociones, recuerdos o imágenes - posibilitan la construcción de lazos que en algún momento pueden dar sentido vivencial al retorno (Sassone, 1988).

En tal sentido, ha sido demostrado que son pocos los migrantes que al partir rompen sus lazos con la tierra de origen (Durand, 2006: 175), donde tienen un hogar, una familia y diversos vínculos afectivos que se fortalecen sin importar la distancia (Cueto, García y Burgueño, 2019). Estas formas de establecer lazos, así como los sistemas de relaciones, campos sociales o redes que atraviesan las fronteras (Levitt y Glick-Schiller, 2004; Portes, 2005; Guarnizo, 1997), ofrecen herramientas para entender las movilidades del retorno bajo la óptica del transnacionalismo, en tanto la transnacionalidad facilita el retorno.

A partir de esta perspectiva teórica el retorno puede entenderse como una aspiración que se nutre de la memoria y de los vínculos emocionales con ese lugar que consideran su patria, pero también como la razón que motiva y empuja a la población migrante a involucrarse en prácticas transnacionales que suponen una constante movilidad entre estos sujetos. De esta manera, el reconocimiento de los diferentes patrones de movilidad llevan a plantear que el "transnacionalismo en sí mismo puede ser conceptualizado como una forma de retorno" (Black y King, 2004, citados en Sinatti, 2011). Cassarino (2004) refuerza este argumento señalando que el retorno es parte de un sistema circular de relaciones económicas y sociales que facilitan la reintegración, al tiempo que se constituye en un recurso para la transferencia de conocimientos, información y membresía.

La noción de "patrones de retorno flexibles" lleva entonces a considerar que el retorno adopta una postura multi-modal, donde entra lo permanente, lo ocasional, lo estacional y lo temporal, lo que según Sinatti (2011) además de agregar una mayor complejidad para su medición plantea otras muchas interrogantes, entre ellas: ¡cómo concebir a esta población migrante que alterna periodos entre el país de origen y de inmigración?, ¿`se trata de transmigrantes o retornados inestables y/o no establecidos? Al respecto, la autora señala que tanto la duración de las estancias, las intenciones al momento de partir y particularmente las percepciones de la población migrante,

EntreDiversidades. Revista de Ciencias Sociales y Humanidades, Vol. 9, Núm. 1 (18), enero-junio 2022. Páginas: 200-222 ISSN-e: 2007-7610. https://doi.org/10.31644/ED.V9.N1.2022.A08 
junto con las de sus familias, son claves para comprender estas movilidades y aclarar el estado, de otro modo confuso, de sus viajes y estancias, en la medida en que la experiencia migratoria está obsesiva y concienzudamente dirigida a un proyecto de vida: volver.

Así las cosas, la distancia entre el ideal de un "retorno definitivo" y las prácticas de estos sujetos migrantes inmersos en un espiral de continuos movimientos a través de los que buscan sustentar su proyecto de retorno hace de dichas prácticas un recurso para acercarse a su objetivo; pues mientras se tantea el terreno para construir un proyecto de retorno no se abandonan las oportunidades y vínculos que se tienen en los lugares en los que se encuentran. Ante ello, emergen también estrategias colectivas que permiten hablar de un "retorno móvil" (Maitilasso, 2017) mediante el cual las personas migrantes buscan mantener y reforzar su presencia aquí y allá a través de relaciones y prácticas sociales que cruzan fronteras, pero con las que gestionan también sus formas de ser y de pertenecer (Levitt y Glick-Schiller, 2004). ${ }^{2}$

Todo lo anterior pone en evidencia que las personas migrantes — que piensan, añoran y buscan regresar - residen en el viaje y/o viven migrando, por lo que conservan y fortalecen los lazos y vínculos con sus lugares de origen. En relación con las diferentes expresiones y productos que las movilidades del retorno adquieren en los trayectos y experiencias migratorias, Durand (2006: 179) establece que hay dos tipos de migrantes a la hora de la partida: los que empiezan la cuenta regresiva del retorno y su único objetivo es volver, y los que, al momento de llegar a su destino, queman las naves y deciden de manera tajante nunca más volver. Aunque la realidad puede cambiar, sostiene el autor, lo cierto es que una mayoría de la población migrante se ubica en la primera opción, lo que también supone que una parte importante de ellos y ellas ha tomado una decisión previa antes de salir y probablemente habrá establecido una estrategia de retorno como "una manera de fijar limites, de proponerse objetivos, de obligarse de algún modo a regresar" (2006: 180).

\section{Consideraciones metodológicas}

Los trayectos migratorios de los sujetos migrantes mexiquenses que se exponen en este trabajo corresponden a personas cuyos casos han sido seguidos durante diferentes momentos y contextos, lo que ha permitido observar, analizar y comprender las expresiones que el retorno adquiere y ha adquirido durante su experiencia migratoria internacional, pues las resignificaciones que como proceso se observan son particularmente sensibles a las condiciones en las que sus proyectos migratorios se insertan y se van ajustando, como por ejemplo, la posibilidad de una reforma migratoria que en la administración de Biden genera esperanzas en materia de derechos y seguridad (Mendoza, 2021), a la vez que reposiciona los proyectos del retorno entre la población no documentada.

La metodología empleada es cualitativa y desde una perspectiva fenomenológica se ha buscado priorizar en las voces y las perspectivas de las y los informantes, con la finalidad de

${ }^{2}$ Las formas de ser se refieren a las relaciones y prácticas sociales en las que participan las personas sin que necesariamente adscriban una identidad, mientras que las formas de pertenecer se expresan en las prácticas o actividades que se desarrollan porque en ellas se reconoce un sentido de pertenencia (Levitt y Glick-Schiller, 2004).

EntreDiversidades. Revista de Ciencias Sociales y Humanidades, Vol. 9, Núm. 1 (18), enero-junio 2022. Páginas: 200-222 ISSN-e: 2007-7610. https://doi.org/10.31644/ED.V9.N1.2022.A08 
profundizar en la subjetividad de estos sujetos migrantes retornados al Estado de México y/o que son participes de diversas prácticas y acciones a través de las que mantienen viva la ilusión del retorno a su país de origen. El uso del método biográfico permitió recopilar narrativas y relatos orientados específicamente a comprender las movilidades del retorno, las particularidades que revisten y las diferentes posiciones que en torno a este proceso se construyen a partir de las experiencias individuales. En otras palabras, Pujadas (2000) señala que:

[...] el material biográfico ayuda a ahuyentar el fantasma de la tipificación de los sujetos como representativos o característicos de un orden sociocultural determinado, mediante la introducción de los sesgos subjetivos y personales, que permiten evidenciar las diferentes posiciones, sensibilidades y experiencias individuales (2000: 130).

De los diversos enfoques que el método biográfico adopta se empleó el relato biográfico para el registro literal de las sesiones con las personas entrevistadas y los testimonios proporcionados (Pujadas, 2000; Sanz, 2005). En estas entrevistas, las preguntas planteadas tenían como propósito recuperar la vivencia subjetiva de la cotidianidad, donde sus protagonistas tomaran posición frente a su narración (Mummert, 2015: 159). Así, cada uno de los sujetos cuya narrativa se expone en este trabajo ha sido entrevistado en tres o más ocasiones — de manera presencial y virtual—, con el propósito de actualizar historias migratorias, pero particularmente con la finalidad de indagar su sentir y sus experiencias frente al retorno.

Las tres personas cuyos relatos se incluyen en este trabajo fueron entrevistadas en diferentes momentos. Mientras uno de los casos ha sido observado y seguido desde 2010, en los otros dos, el primer acercamiento se realizó en 2017 y 2019, respectivamente. Con ello ha sido posible conocer las configuraciones que los retornos adquieren ante situaciones específicas como la crisis económica de 2008, así como las medidas antiinmigrantes en las administraciones de Obama y Trump y la reciente crisis de salud por el virus SARS-CoV-2. De esta manera, es posible hablar de proyectos de retorno en "sujetos ubicados [...] [que] viven, observan, narran e interpretan la realidad desde sus posicionamientos específicos" (Hirai, 2012: 101). Se trata entonces de "sujetos posicionados socialmente" (Rosaldo, 2000: 196) que reinterpretan sus retornos en función de la ubicación o posición en la que se encuentran antes de emigrar, durante la propia inmigración o en el retorno mismo. Al respecto, Hirai y Sandoval (2016: 278) proponen centrar la mirada en la dimensión subjetiva, tanto por la interpretación y reinterpretación de las historias migratorias, las emociones y la pertenencia como por la actualización constante de los proyectos de vida, los significados y los sentidos.

Las entrevistas realizadas corresponden a personas residentes y migrantes sin documentos que han vuelto a sus lugares de origen por motivos diversos — voluntaria e involuntariamente-, con estancias en Estados Unidos y en el Estado de México en patrones de retorno flexibles, retornos móviles o inestables. Así también, con el propósito de comprender los retornos y las presencias imaginadas se incorpora el caso de un sujeto migrante cuyo proyecto de retorno no se ha concretado, pero se sostiene a partir de los lazos con las personas y el lugar con el que tiene vínculos emocionales e históricos. Como podrá leerse más adelante, la diversidad

EntreDiversidades. Revista de Ciencias Sociales y Humanidades, Vol. 9, Núm. 1 (18), enero-junio 2022. Páginas: 200-222 ISSN-e: 2007-7610. https://doi.org/10.31644/ED.V9.N1.2022.A08 
en las características de cada caso tiene como finalidad dar cuenta de sus especificidades para comprender las movilidades del retorno y las expresiones que tienen en términos de lo real, lo virtual, lo imaginado, lo deseado, lo forzado y lo negado.

\section{Retorno en el Estado de México}

Una breve aproximación a la dinámica migratoria del Estado de México y los principales circuitos migratorios puede observarse según el registro de las matrículas consulares de población mexicana en Estados Unidos. De acuerdo con el Anuario de Migración y Remesas (CONAPO y Fundación BBVA Bancomer, 2020), de las 794748 matrículas consulares registradas en 2018, el Estado de México se situó en la octava posición a nivel nacional, con 5.0\% del total (39 449), de las cuales $37.6 \%$ corresponden a mujeres (14 847) y 62.4\% a hombres $(24602)$.

A nivel municipal destacan Nezahualcóyotl (9.4\%), Tejupilco (9.2\%), Ecatepec (5.9\%), Tlalnepantla $(5.8 \%)$ y Tlatlaya $(4.4 \%)$, población que en su mayor parte se encuentra en California (23.7\%), Texas (19.0\%), Illinois (14.0\%), Florida (4.1\%) y Nueva York (3.7\%). Todas ellas son cifras que corresponden con los casos que se presentan en este trabajo, por tratarse de personas que radican o radicaron en Waukegan, Woodstock y Chicago, Illinois.

\section{Gráfica 1. Causas del retorno de la población migrante mexiquense, 2005-2020}

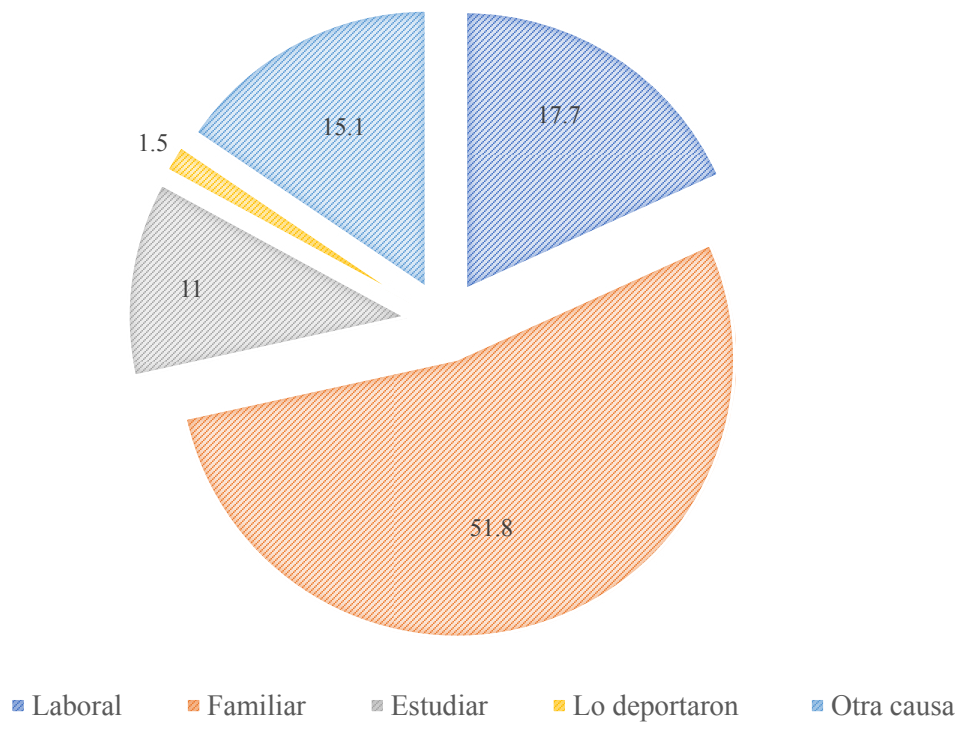

Fuente: Elaboración propia con base en los resultados del Censo General de Población y Vivienda, 2020 (INEGI, 2020).

De acuerdo con los resultados del Censo de Población y Vivienda 2020 del Instituto Nacional de Estadística y Geografía la entidad mexiquense tiene una importante dinámica migratoria. Del total de la población migrante internacional a nivel nacional (802 807), el Estado de México 
se posicionó en el cuarto lugar, con aproximadamente 5.4\% (43 459). Una misma situación se observa en relación con la población migrante de retorno, situándose en el quinto lugar, con alrededor de 6.5\% (11 622) de los 178072 retornados durante el periodo 2015-2020. Las causas que explican el retorno de esta población, según esta misma fuente, son cuestiones familiares principalmente, seguido de temas laborales y otras razones tales como inseguridad, violencia, desastres naturales, entre otros aspectos (ver Gráfica 1).

En un mayor nivel de especificidad, según la encuesta "Dinámicas de la emigración y el retorno en comunidades rurales del sur del Estado de México, 2017”, de 476 hogares en viviendas de Coatepec Harinas, Tenancingo, Tonatico y Villa Guerrero en los que se aplicó el cuestionario, en aproximadamente $286(60.1 \%)$ de estos hogares, por lo menos uno de sus integrantes cuenta con experiencia migratoria internacional.

A nivel de individuo se obtuvo un estimado de 352 sujetos cuyos retornos de Estados Unidos en su mayor parte se asocian con motivos personales de diversa índole (24.1\%), así como al hecho de extrañar a la familia (20.9\%), haber sido deportado por autoridades migratorias de Estados Unidos (13.5\%) y/o haberse quedado sin trabajo (9.7\%). En menor proporción, aunque no por ello menos importante, se ubican también las y los que señalan haber regresado por situaciones de salud, así como por cuestiones de racismo, miedo y/o el sentir estar perdiendo libertad en contextos discriminatorios y antiinmigrantes (ver Gráfica 2).

\section{Gráfica 2. Motivos asociados con el retorno de Estados Unidos al Estado de México}

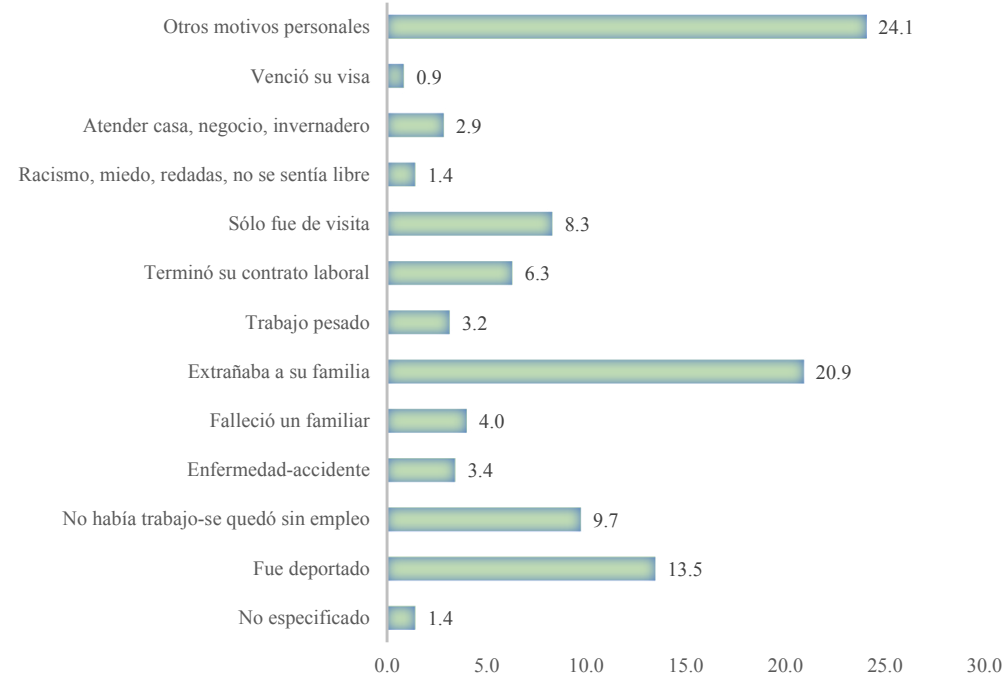

Fuente: Elaboración propia con base en Jardón (2017), encuesta "Dinámicas de la emigración y el retorno en comunidades rurales del sur del Estado de México, 2017”.*

* Encuesta aplicada a un total de 476 hogares en comunidades rurales con tradición migratoria de los municipios de Coatepec Harinas, Villa Guerrero, Tonatico y Tenancingo del Estado de México. 


\section{La descripción de los casos}

En el siguiente apartado se exponen los casos de tres personas migrantes, cuyos trayectos y experiencias migratorias permiten comprender las movilidades del retorno, así como las expresiones y los sentidos que este adquiere a partir de las especificidades que le son propias a cada uno de ellos.

\section{¿Retornos móviles e inestables? Vivir migrando entre México y Estados Unidos: el caso de Néstor}

La complejidad de las movilidades del retorno podemos observarla en el caso de Néstor, migrante originario de Las Vueltas, Coatepec Harinas. En 1975, Néstor emigró sin documentos por primera vez a Woodstock, Illinois, con la "ilusión de ganar unos centavos y tener un poquito de mejor vida". Después de una estancia de aproximadamente un año regresó a su comunidad de origen para emigrar nuevamente en 1979. En esta segunda ocasión su estancia en Estados Unidos se prolongó por aproximadamente dos años, pues fue en 1981 cuando regresó para casarse y permanecer en su pueblo por un tiempo de casi tres ańos. Durante estos dos primeros viajes a Estados Unidos el regreso al lugar de origen era parte de la experiencia migratoria de Néstor, lo que se explica por el patrón migratorio de tipo circular que caracterizaba a la migración de la población mexicana en esos años (Corona, 1993).

Néstor logró regularizar su estatus migratorio en 1986 por medio de la denominada "amnistía" (Immigration Reform and Control Act, también conocida como Ley Simpson-Rodino), mediante la que se vieron favorecidos un número importante de personas migrantes que demostraron haber residido y trabajado en Estados Unidos durante un periodo de seis años (González y Escobar, 1990). Desde entonces, ir y venir entre uno y otro país ha sido una práctica recurrente para Néstor, particularmente después de 1997, cuando su esposa Silvia “ya con papeles" se fue a vivir a Estados Unidos. De acuerdo con Néstor, el hecho de mantener los vínculos con su pueblo responde al arraigo y sentido de pertenencia que tiene para con su lugar de origen, mismo que expresa diciendo "yo me considero que todavía soy de este pueblo".

En 2011, año en el que se entrevistó por primera vez a Néstor, se encontraba de regreso con su esposa y dos de sus hijos en Las Vueltas. En esa ocasión el viaje no necesariamente estaba vinculado con las visitas anuales que él y su familia realizan durante el mes de mayo para asistir a la fiesta patronal del pueblo, para la que cooperan y se organizan como comunidad por la importancia que esta celebración tiene a nivel municipal (Jardón y Hernández, 2019). En ese año la familia se encontraba de vuelta porque Néstor y uno de sus hijos se habían quedado sin trabajo en Estados Unidos como consecuencia de la crisis económica internacional de 2008, que afectó significativamente a la población migrante documentada y no documentada, dada su concentración en los sectores que resultaron mayormente afectados en sus niveles de productividad y empleo (Papademetriou y Terrazas, 2009).

Durante 2009 y 2010 Néstor consiguió un empleo temporal y en el que percibía el salario mínimo, siendo sus ahorros y el apoyo familiar lo que permitió que en su momento no resintieran en gran medida los efectos de la crisis. No obstante, en 2011, las dificultades económicas y la falta de empleo los llevó a tomar la decisión de volver para permanecer un tiempo en Las Vueltas, lugar

EntreDiversidades. Revista de Ciencias Sociales y Humanidades, Vol. 9, Núm. 1 (18), enero-junio 2022. Páginas: 200-222 ISSN-e: 2007-7610. https://doi.org/10.31644/ED.V9.N1.2022.A08 
en el que tienen una vivienda que han construido con lo trabajado en Estados Unidos — siguiendo a Cassarino (2004), aquí se tiene un ejemplo de la preparación y movilización de recursos para el retorno- - A decir de Néstor, esto ayudaría por lo menos a no tener que pagar renta, además de que en este lugar podrían contar con el apoyo de su hermano que ha permanecido en Las Vueltas trabajando los terrenos de la familia. En este contexto, el retorno se posicionó como una estrategia de reproducción familiar facilitada por "los lazos de pertenencia reproducidos desde el destino con la comunidad de origen” (Cueto, García y Burgueño, 2019: 249).

Por ejemplo, mi hermano que está aquí [en Las Vueltas], él tiene muchas huertas chicas que apenas le van a empezar a ayudar, él apenas va sobreviviendo, y pues nosotros vamos a decir estamos en la esperanza de que él nos apoye, él está trabajando todos los terrenos a la cuenta que eran de mi papá, entonces el día que regresemos o ahora que estamos de regreso tiene que apoyarnos.

A nosotros nos ha ido mal [en Estados Unidos], qué le puedo decir, para nosotros ha sido mal, yo tengo dos años, este año pasado trabajé ocho meses y ganando el mínimo. Yo trabajé diez años en dos trabajos, entonces tratamos de ahorrar un poquito, eso nos ha ayudado a que no estemos completamente en crisis. Por eso estamos de regreso, pues aquí por lo menos tenemos esta casa que hemos construido gracias a lo que hemos juntado estando allá [en Estados Unidos] (Néstor, 2011, Las Vueltas, Coatepec Harinas, Estado de México).

No obstante, la idea de Néstor y de su familia de permanecer un tiempo en Las Vueltas se sostuvo por menos de seis meses, pues en 2012 ya se encontraban de regreso en Woodstock, dado que con la recuperación económica en Estados Unidos tanto él como su esposa consiguieron empleo, entonces se involucraron nuevamente en la dinámica de volver a su pueblo por lo menos una vez al año.

En este proceso de vivir migrando Néstor y su esposa señalaron que cuando sus dos hijos menores contaran con la edad para vivir de manera independiente en Estados Unidos podría ser el momento en el que ambos retornarían para residir en Las Vueltas, aunque ir y venir entre uno y otro país sería un proceso que tendría continuidad en sus vidas, con el fin de visitar por un tiempo a sus hijos que han decidido establecerse en Estados Unidos.

Primero Dios sí pensamos quedarnos a vivir aquí [en Las Vueltas], nada más que en cuanto nuestros hijos se puedan valer por sí mismos ya, como quiera no me voy a quedar permanentemente aquí [en Las Vueltas] porque mis hijos se van a quedar allá [en Estados Unidos], vamos a ir una o dos veces al año, para quedarnos un mes o dos (Néstor, 2011, Las Vueltas, Coatepec Harinas, Estado de México).

Después de 2011, por las visitas que he realizado a la comunidad, así como por las entrevistas de seguimiento para actualizar la información, ha sido posible observar que los "retornos móviles" de Néstor y Silvia han tenido continuidad, con estancias prolongadas en Estados Unidos y retornos regulares a México. Los regresos a Las Vueltas revisten importancia para Néstor y su esposa, en la

EntreDiversidades. Revista de Ciencias Sociales y Humanidades, Vol. 9, Núm. 1 (18), enero-junio 2022. Páginas: 200-222 ISSN-e: 2007-7610. https://doi.org/10.31644/ED.V9.N1.2022.A08 
medida en que ambos participan de la organización y recaudación de fondos para la celebración de la fiesta patronal, lo que de alguna manera ha permitido la continuidad en el ejercicio de diversas prácticas transnacionales de tipo social, económico y cultural. Ambos mantienen la idea de seguir siendo parte de las actividades que se realizan en su pueblo, conservar sus lazos y no sentirse ajenos a este lugar en caso de que ocurra el proyecto de retorno para vivir en Las Vueltas, pues a la fecha Néstor y Silvia no han regresado para "establecerse definitivamente" en su pueblo, a pesar de que sus hijos trabajan y son económicamente independientes.

Si bien la crisis sanitaria por la covid-19 los ha posicionado en la paradoja de la inmovilidad en la era de la movilidad, vemos que el vivir transnacional de la pareja facilita los retornos y fortalece los lazos con el lugar de origen y de salida en la búsqueda por concretar su proyecto de volver, al mismo tiempo que amplían los recursos y fortalecen también los vínculos en el lugar en el que se encuentran.

\section{Retornos permanentes. Volviendo a México, pero yéndose a Estados Unidos: el caso de Ana}

El caso de Ana corresponde al de una mujer migrante que regresa a México luego de haber sido deportada de Estados Unidos en junio de 2016 con una penalidad de veinte ańos en los que no puede volver a ese país. En 2001, cuando logró cruzar y llegar sin documentos a Chicago, Illinois, ella consideraba que su estancia sería de uno o dos años, pues su intención era trabajar, juntar dinero y regresar con sus cuatro hijos que se habían quedado al cuidado de su mamá en Jalisco. En un primer momento, Ana pensó y planificó su retorno, es decir, emigró pensando en volver. Sin embargo, su experiencia migratoria reposicionó significativamente la idea de retornar de Chicago a Jalisco, o al menos al Estado de México, lugar en el que vivió por varios años antes de emigrar a Jalisco por diversas situaciones familiares. ${ }^{3}$

La estancia de Ana en Estados Unidos se prolongó por aproximadamente 15 años, tiempo en el que formó otra familia, estudió, trabajó y se convirtió en activista defensora de los derechos laborales de la población migrante. Durante su permanencia en el país Ana consideró estar viviendo el "sueño americano", por lo que estar de regreso en México no le ha sido fácil. En un esfuerzo por comprender que "su vida no puede acabarse por una deportación" ha buscado reinsertarse en el municipio de Nezahualcóyotl del Estado de México, lugar que ella considera "le abrió las puertas" al encontrarse de regreso de manera forzada.

Durante el tiempo que Ana tiene en México ha trabajado por cuenta propia en su taller de serigrafía, Deportados Brand, proyecto que inició en 2016 con el apoyo para iniciativas de ocupación por cuenta propia que recibió de la Secretaría del Trabajo y Fomento al Empleo de la Ciudad de México (STyFE). A la par de Deportados Brand, Ana ha dado continuidad a su papel como activista con la comunidad migrante deportada en México, creando para ello el Colectivo Deportados Unidos en la Lucha (DUL), un espacio que le ha permitido gestionar sus propias emociones sobre la posibilidad de regresar a Estados Unidos, la deportación, la vergüenza, la

\footnotetext{
${ }^{3}$ La primera entrevista con Ana fue en 2017 en Ciudad de México. En enero de 2020 se entrevistó nuevamente en Nezahualcóyotl. A partir de entonces se ha dado seguimiento al caso de manera virtual a través de llamadas, chat y Facebook.
}

EntreDiversidades. Revista de Ciencias Sociales y Humanidades, Vol. 9, Núm. 1 (18), enero-junio 2022. Páginas: 200-222 ISSN-e: 2007-7610. https://doi.org/10.31644/ED.V9.N1.2022.A08 
criminalización y el estigma, sentimientos que ella también enfrentó como migrante deportada (Jardón y Ronzón, 2020) y que se constituyen en un entramado de emociones que sustentan las percepciones cambiantes sobre el retorno, en este caso hacia el vecino país del norte.

Estas expresiones, aunque no son exclusivas, tienden a ser más álgidas entre las personas que retornan después de varios años de ausencia y/o que vuelven de manera forzada, como lo es el caso de Ana, regresando a espacios que no necesariamente son comunidades de retorno y donde son estigmatizados y ridiculizados por su ahora forma de hablar, de vestir, sus creencias, actitudes, prácticas y aspiraciones (Majidi, 2020: 3).

Es por ello por lo que, como colectivo, la lucha de Ana y sus "compas", como ella llama a los participantes del mismo, tiene como propósito apoyar los procesos de reinserción de estas personas que retornan de manera forzada, abanderando la idea de que "es más que solo regresar a Estados Unidos”.

La idea es poder presentar ya esta visión más amplia y que los compas pues traten de despertar esa conciencia y que vean que no es más que solo regresar nuestra lucha, es más amplia la lucha que solamente el poder estar de nuevo allá [en Estados Unidos]. Y pues eso es lo que nosotros estamos trabajando, Deportados Unidos ya nos estamos enfocando en este panorama más amplio, inserción y reinserción (Ana, 2020, Nezahualcóyotl, Estado de México).

Trabajar en estas acciones individuales y colectivas le han permitido de alguna manera a Ana, como ella misma dice, "dejar de mirar al norte" para construir su vida en México, además de reconocer que a diferencia de otros compas "no es su obsesión regresar a Estados Unidos ni en lo que gasta su vida”. A pesar de ello, por contradictorio que pueda parecer, la narrativa de Ana permite entender que la esperanza de volver se mantiene. Esa noción se sostiene en acciones como el hecho de negarse a amueblar su departamento en Nezahualcóyotl, toda vez que para ella "su casa, su hogar, su arraigo y su pertenencia” está en Chicago. Un hogar al que ella considera que "tarde o temprano va a regresar", pues aunque Ana señala que ella "quiere hacer las cosas diferentes y no agarrar un coyote para volver", diversos estudios muestran que la deportación no siempre es un impedimento para re-emigrar, dado que una mayoría de las personas deportadas quieren, buscan, intentan o se van de nuevo, particularmente cuando se tienen y se conservan los vínculos con el país del que fueron expulsados (Schuster y Majidi, 2013; Galvin, 2015), como en el caso de Ana, cuyos dos hijos nacidos en Estados Unidos la impulsan y la motivan a regresar.

Mi concepto de lo que yo entiendo de hogar está en Chicago, para mí ha sido tan difícil que ahorita yo ya empiezo a amueblar mi casa, mi departamento donde estoy, yo me negaba a amueblarlo o a comprar cosas, ¿para qué si yo me voy a regresar?, tarde o temprano me voy a regresar, ¿para qué compro eso?, ¿para qué pongo el otro?, si mi casa está allá y allá están mis cosas, y me ha costado trabajo porque yo sigo viendo mi casa allá (Ana, 2020, Nezahualcóyotl, Estado de México).

EntreDiversidades. Revista de Ciencias Sociales y Humanidades, Vol. 9, Núm. 1 (18), enero-junio 2022. Páginas: 200-222 ISSN-e: 2007-7610. https://doi.org/10.31644/ED.V9.N1.2022.A08 
En la narrativa de Ana podemos identificar ese proceso de ansiedad que le genera estar en el Estado de México, donde ha buscado reinsertarse bajo el entendido de que la vida continúa, aunque ello no necesariamente implica que en su proyecto de vida se desdibuje la idea de volver a Estados Unidos, esperanza que se avivó con la participación de su colectivo DUL y otras organizaciones en la tormenta de tweets realizada en enero de 2021 con la finalidad de exigir el cumplimiento de las promesas de campaña de Biden para la reunificación familiar de las y los deportados durante la administración de Obama y Trump (Red Unidos, 2021).

Es tu vida la que está ahí, y no es fácil, no es fácil, a mí me cuesta hacer videollamadas a veces porque mi casa, veo mis cosas y es tan difícil y es difícil para mí y para mis hijos también. Parece que la casa está detenida en el tiempo, no han tirado ni mi cepillo de dientes, ni mis pinzas, ni mis cosas que se quedaron ahí, ahí siguen porque ellos también tienen la esperanza de que tal vez algún día uno regrese. Un día hablé con una psicóloga, le dije Mari, no sé qué sea más bueno, o dejarles claro que ya no voy a regresar, que no hay posibilidades tanto para mí, como para que mis hijos lo asimilen ya y que me manden mis cosas y como que nunca existí, o dejarlo así, que de alguna manera es un consuelo. Al final tengo que dejar las cosas así, porque es un pequeño consuelo a romper de tajo (Ana, 2020, Nezahualcóyotl, Estado de México).

Así las cosas, aunque en su narrativa Ana señale que ya no regresará a Estados Unidos, en la práctica pareciera estar optando por quedarse, por permanecer en México, pero con imaginarios que en todo momento se alimentan de la ilusión de volver a Estados Unidos. Ejemplo de ello puede observarse en las publicaciones que recientemente ha realizado en su red social de Facebook, con imágenes de la Ciudad de Chicago que usa para reconocer su "hogar", el lugar donde está su corazón y su felicidad: "home is where the heart is" (el hogar está donde el corazón está), escribe en una de sus publicaciones.

\section{Retornos imaginados. Quedándose en Estados Unidos, pero yéndose a México: el caso de Omar}

Las ausencias y presencias que acompañan al acto de emigrar y/o de encontrarse in between (en medio) de dos condiciones es uno de los principales aspectos observados en la historia migratoria de Omar. Como él mismo señala, el hecho de "permanecer en Estados Unidos anhelando regresar a México" sustenta sus esfuerzos por mantenerse vinculado con su lugar de origen, en tanto su proyecto de vida es volver. ${ }^{4}$

Omar emigró a Estados Unidos por primera vez en 2001, cruzó sin documentos, siendo soltero y con el objetivo de llegar a Phoenix. Su estancia en ese lugar fue de cuatro años y regresó a su municipio de origen, aunque por problemas familiares se trasladó a Cancún, lugar en el que trabajó por un tiempo de 10 meses. Volvió a Ixtapan de la Sal, pues falleció su abuela paterna, quien lo cuidó y con quién vivió desde niño y hasta antes de irse a Estados Unidos por primera vez.

${ }^{4}$ Las primeras entrevistas con Omar fueron en 2017 de manera virtual. En 2019 se realizó trabajo de campo en Estados Unidos, por lo que fue posible entrevistarlo y seguirlo en diversas de sus actividades.

EntreDiversidades. Revista de Ciencias Sociales y Humanidades, Vol. 9, Núm. 1 (18), enero-junio 2022. Páginas: 200-222 ISSN-e: 2007-7610. https://doi.org/10.31644/ED.V9.N1.2022.A08 
En 2006, tras la pérdida de su abuela y el hecho de no ser aceptado por sus tíos en Ixtapan de la Sal, decidió emigrar nuevamente. Ayudado por la hija de su vecina que vivía en Arizona ${ }^{5}$ y con el pago realizado por su mamá desde Nueva York, llegó nuevamente a Phoenix. En ese lugar empezó a trabajar en el mismo restaurante donde obtuvo empleo la primera vez que estuvo en Estados Unidos, pero después de visitar a su mamá en Nueva York se trasladó a Waukegan, Illinois, ciudad en la que radican un número importante de migrantes mexiquenses, particularmente originarios de Ixtapan de la Sal.

Desde el momento que yo decidí que quería venir otra vez a Estados Unidos yo quería tener una segunda oportunidad de lo que había desperdiciado en esos años [primera vez que estuvo en Estados Unidos], cuando yo decidí que quería venir acá [en Estados Unidos] otra vez yo ya venía con la programación en mi computadora de lo que yo quería, yo ya sabía a lo que venía, de hecho mi estancia aquí no iba a ser mucha, quería que mi vida fuera corta en este país, pero al final de cuentas es demasiado larga, yo ya llevo 13 años aquí (Omar, 2019, Chicago, Estados Unidos).

Antes de partir, como puede leerse en la narrativa de Omar, la noción del retorno aparece en tanto emigra con una meta establecida, sin necesariamente fijar una temporalidad determinada, pero con la idea de permanecer un corto periodo de tiempo en ese país. Sin embargo, como se señaló con anterioridad, durante la inmigración los retornos se transforman en relación con lo incierto. Durante su estancia en Waukegan, Omar consiguió trabajo como cajero en McDonald's: “trabajaba en dos McDonald's para juntar rápido dinero y ver si ya me largaba a mi rancho".

Los planes del retorno fueron cambiando cuando obtuvo un trabajo bien remunerado y que a la fecha sigue siendo su principal empleo, cajero en una casa de cambio de divisas, pero la decisión de retornar se constituyó en un dilema luego de haberse unido — al igual que lo expone Espinosa (1998) en su estudio de caso-, así como después de tener a sus dos hijas y de haber comprado una vivienda para la seguridad y bienestar de su familia. Así fue como una estancia que se pensó corta se prolongó por un tiempo de aproximadamente 15 ańos, por lo que el retorno para Omar se trata de un proyecto que no se ha concretado.

A pesar de ello, Omar no ha perdido el contacto con algunos de sus familiares en México, especialmente con su abuela materna y su media hermana, quienes viven en la ciudad de Toluca, así como con amistades en Ixtapan de la Sal. Los vínculos los mantiene con la intención de facilitar su retorno, en caso de que este ocurra en algún momento. El proyecto de retorno ha sido una constante en la vida de Omar, de manera que ha buscado adquirir propiedades en el Estado de México, al tiempo que ha construido su casa en las afueras de Ixtapan, una casa conocida entre los lugareños como "la casa blanca". Se trata de un espacio que según establece Sayad (2010:269) "es su obsesión por borrar su emigración [...] pues a menudo, la casa edificada en el país de origen no tiene otra función más que la de recordar la presencia desaparecida, y negar dicha desaparición”.

${ }^{5}$ El tiempo en el que Omar se encontraba de regreso en Arizona coincide con el ambiente de hostilidad hacia la población migrante, que en 2006 se materializó por lo menos en cuatro leyes con prohibiciones de acceso a diferentes servicios. En 2008, su posicionamiento como el estado más racista motivó la migración de mexicanos a otros estados de la Unión Americana (Torre, 2016).

EntreDiversidades. Revista de Ciencias Sociales y Humanidades, Vol. 9, Núm. 1 (18), enero-junio 2022. Páginas: 200-222 ISSN-e: 2007-7610. https://doi.org/10.31644/ED.V9.N1.2022.A08 
Le dije a mi abuela: "quiero un terreno en Ixtapan de la Sal", y ella me dijo: "no, tú eres el pato feo, allá nadie te quiere". Entonces le dije a un amigo: "búscame un terreno", para eso me dijo una persona tiene dos terrenos uno de 150 y otro en 90 mil, le dije "quiero el de 90 mil [pesos]". Le dije abuelita: "quiero ese terreno", entonces mi abuelita no quería y le dije que le diera el dinero a mi amigo y que él comprara el terreno. Fue, se entrevistó con el amigo, fue a ver el terreno y me dijo ese terreno está refeo, está lejos, y yo con la nostalgia de un paisano inmigrante, y yo con las ganas de querer regresar a mi pueblo y le dije quiero ese terreno, no me importa (Omar, 2019, Chicago, Estados Unidos).

Aunado a ello, las redes sociales han facilitado la vinculación de Omar con otras personas de Ixtapan, en la medida en que se mantiene activo en grupos de Facebook, además de que está buscando implementar un proyecto de taller de costura con el que busca emplear personas que trabajen en la elaboración de productos artesanales, que también él pueda vender en Estados Unidos.

En su anhelo por regresar a México, Omar dice estar ahorrando para ese momento, con la finalidad de facilitar su reinserción social y laboral. Sin embargo, su esposa no quiere regresar a México, además de que él mismo considera tener miedo e inseguridad por el choque cultural, por su forma de hablar, por el estilo de vida que ahora lleva en Estados Unidos, pero especialmente porque "no veo el mismo futuro para sus hijas en México, les negaría oportunidades en caso de regresar". Todo ello hace entonces que el retorno por ahora se quede como un proyecto, que para Omar cobra también esperanzas con la posibilidad de una reforma migratoria en la administración de Biden, pero que ante las condiciones actuales se orientan más al hecho de quedarse en Estados Unidos pero yéndose a México, por lo menos desde sus planes, desde sus imaginarios, desde sus vínculos y las muchas emociones que le generan el pensar y trabajar para estar de regreso en su lugar de origen.

\section{Conclusiones}

Yo le digo mi intención no es estar en Estados Unidos de por vida, o sea mi intención es arreglarles [sus documentos] a ellos [sus hijos], si se lograra, si pensamos trabajar un par de años juntos, darle duro y regresar [a México]. Ese es el plan, no sabemos en el camino qué nos vayamos a encontrar, alomejor arreglo y le gusta vivir por allá [Estados Unidos] y nos quedamos, al cabo es estar bien, no se puede estar a fuerzas, pero yo mi idea es quedarme aquí [Tenancingo] (Luis, 2020, Tenancingo, Estado de México).

Para concluir, retomamos un breve fragmento de la entrevista con un migrante documentado originario de Tenancingo, Estado de México, con la finalidad de hacer énfasis en el retorno como una motivación o intención regularmente manifiesta en los proyectos migratorios de esta

EntreDiversidades. Revista de Ciencias Sociales y Humanidades, Vol. 9, Núm. 1 (18), enero-junio 2022. Páginas: 200-222 ISSN-e: 2007-7610. https://doi.org/10.31644/ED.V9.N1.2022.A08 
población. Como aluden Massey, et al. (1991: 15) estos patrones se asocian con un apego sentimental al terruño que se expresa en una ideología que alienta el retorno.

Además, la narrativa de Luis ofrece una aproximación a lo ya planteado por Cassain (2019), en torno al carácter procesual de la migración con "retornos que se hacen" a partir de las circunstancias específicas que vive y en las que se encuentra inserto cada sujeto migrante al momento de emigrar, como durante su estancia en el país de destino e incluso durante el retorno mismo, pero también en función de la relación que los retornos pueden tener con lo incierto. Como ha sido señalado por Luis, aunque su intención sea volver, es posible que sus hijos quieran permanecer en Estados Unidos, lo que impactaría entonces en el proyecto de retorno de su familia. Es el mismo caso que aborda Espinosa (1998), donde las posiciones encontradas entre Quico Correa, Ana María y sus cuatro hijos nacidos en Estados Unidos ponen de manifiesto que los sentidos que el retorno adquiere son asignados por el sujeto migrante, pero también por las personas que lo rodean, lo que construye entonces la noción del dilema entre volver y permanecer.

Así, se puede decir que los casos aquí expuestos ponen de manifiesto la prolongación en el tiempo de estancia entre la población migrante que no tiene documentos (Alarcón, et al., 2009), pero también entre la que cuenta con estos, quedando en cierto sentido atrapados en territorio norteamericano ante los costos, los riesgos, la incertidumbre y las muchas circunstancias que reposicionan la idea de volver.

De esta manera, entre lo imprevisto e improbable, los retornos que se piensan temporales, como en todos los casos aquí expuestos, pueden adquirir más visos de permanencia. En otras palabras, se trata entonces de un "volver" que se reposiciona constantemente frente a las circunstancias, particularidades y contextos en los que se ven inmersos los sujetos migrantes, especialmente considerando que "cada proyecto es de su tiempo que lo acondiciona y lo ahorma" (Izquierdo, 2000: 43).

En suma, los tres casos presentados en este trabajo ofrecen un acercamiento a la propuesta conceptual sobre las movilidades del retorno como una categoría analítica para comprender la complejidad de los regresos de las personas migrantes, en función de los diversos patrones de movilidad, los motivos, las temporalidades, las representaciones y los sentidos asignados a estos desplazamientos. Reflexionar sobre el retorno desde la perspectiva de los sujetos entrevistados permite sustentar la noción del regreso — visitas cortas, temporales, ocasionales, circulación en campos transnacionales - que ocurre por motivos diversos e interdependientes a los lugares y con las personas con las que esta población sostiene algún tipo de vínculo emocional y social, por lo que entonces habrán de mantenerse, en la mayor parte de los casos, prácticas de diversa índole que permitan asegurar los lazos con estos espacios de vida, con vidas simultáneas en el aquí y el allá, envueltos en la liminalidad de la experiencia migrante que supone encontrarse en medio (in between), con la conciencia de ser de ambos lugares, con ausencias y presencias en el destino y el origen, pues en todo caso es posible que en algún momento estas prácticas posibiliten que el retorno ocurra al lugar que consideran su hogar, sea este en México o en Estados Unidos.

Así, en las movilidades del retorno de estas personas migrantes se observa esa tensión entre volver, permanecer, pertenecer, establecerse y re-emigrar. La incertidumbre y las emociones que acompañan a estos desplazamientos generan también ansiedades ante el posible retorno al

EntreDiversidades. Revista de Ciencias Sociales y Humanidades, Vol. 9, Núm. 1 (18), enero-junio 2022. Páginas: 200-222 ISSN-e: 2007-7610. https://doi.org/10.31644/ED.V9.N1.2022.A08 
terruño imaginado, al que se desea volver, siendo así las emociones una ventana a través de las que se asoman los sentidos y significados del retorno, como puede leerse en los tres casos aquí expuestos. En suma, según lo establecen King y Christou (2011), es necesario reflexionar los retornos más allá de una mirada simplista situada en un movimiento corporal, toda vez que las emociones, redes, actividades, estilos de vida e ideologías que involucran las vidas duales de estos sujetos migrantes requieren de nuevas conceptualizaciones y aproximaciones para su comprensión (Cavalcanti y Parella, 2013).

\section{Bibliografía citada}

Alarcón, Rafael, et al. (2009). "La crisis financiera en Estados Unidos y su impacto en la migración mexicana”. Migraciones Internacionales [en línea], 5 (16), pp. 193-210. Disponible en: https://migracionesinternacionales.colef.mx/index.php/migracionesinternacionales/ article/view/1108 (Consultado el 6 de agosto de 2021).

Anguiano Téllez, María Eugenia (2000). "Reseña Bibliográfica. El dilema del retorno. Migración, género y pertenencia en un contexto transnacional”. Frontera Norte [en línea], 12 (23), pp. 165-168. Disponible en: https://fronteranorte.colef.mx/index.php/fronteranorte/ article/view/1399 (Consultado el 11 de enero de 2021).

Bhabha, Homi K. (2002 [1994]). El lugar de la cultura. Buenos Aires, Argentina: Ediciones Manantial.

Cassain, Laura (2019). Volver. Trayectorias migratorias y procesos de retorno de España a Argentina. Tesis para obtener el grado de Doctorado en Sociología y Antropología, Facultad de Ciencias Políticas y Sociología, Universidad Complutense de Madrid. Disponible en: https://eprints.ucm.es/id/eprint/50849/1/T40790.pdf (Consultado el 27 de octubre de 2020).

Cassarino, Jean-Pierre (2004). "Theorizing Return Migration: The Conceptual Approach to Return Migrants Revisited”. International Journal on Multicultural Societies [en línea], 6 (2), pp. 253-279. Disponible en: https://hal.archives-ouvertes.fr/hal-01237439/ document (Consultado el 7 de agosto de 2021).

Cavalcanti, Leonardo y Parella, Sònia (2013). "El retorno desde una perspectiva transnacional". Revista Interdisciplinar da Mobilidade Humana [en línea], 21 (41), pp. 9-20. Disponible en: http://remhu.csem.org.br/index.php/remhu/article/view/401 (Consultado el 27 de octubre de 2020).

Consejo Nacional de Población (CONAPO) y Fundación BBVA (2020). Anuario de Migración y Remesas 2020 [en línea]. Ciudad de México, México: Fundación BBVA, Consejo Nacional de Población. Disponible en: https://www.bbvaresearch.com/wp-content/ uploads/2020/10/Anuario Migracion_y Remesas 2020.pdf (Consultado el 16 de marzo de 2021).

EntreDiversidades. Revista de Ciencias Sociales y Humanidades, Vol. 9, Núm. 1 (18), enero-junio 2022. Páginas: 200-222 ISSN-e: 2007-7610. https://doi.org/10.31644/ED.V9.N1.2022.A08 
Corona Vázquez, Rodolfo (1993). "La migración de mexicanos a los Estados Unidos: cambios en la década de 1980-1990”. Revista Mexicana de Sociología [en línea], 55 (1), pp. 213-233. doi: https://doi.org/10.2307/3541001 (Consultado el 21 de septiembre de 2020).

Cueto Calderón, José Salvador, Ismael García Castro y Nayeli Burgueño Angulo (2019). "Retorno actual como estrategia resiliente de sobrevivencia de familias mexicanas establecidas en Arizona”. Revista NuestrAmérica [en línea], 7 (13), pp. 241-263. Disponible en: https://dialnet.unirioja.es/servlet/articulo? codigo=6809039 (Consultado el 10 de septiembre de 2020).

Durand, Jorge (1996). El norte es como el mar. Entrevistas a trabajadores migrantes en Estados Unidos. México. D.F., México: Universidad de Guadalajara. Disponible en: http:// www.catedrajorgedurand.udg.mx/es/contenido/el-norte-es-como-el-mar-entrevistastrabajadores-migrantes-en-los-estados-unidos (Consultado el 18 de enero de 2021).

Durand, Jorge (2006). "Los inmigrantes también emigran: la migración de retorno como corolario del proceso". Revista Interdisciplinar da Mobilidade Humana [en línea], 14 (26/27), pp. 167-189. Disponible en: http://remhu.csem.org.br/index.php/remhu/article/view/40 (Consultado el 18 de enero de 2019).

Espinosa, Víctor M. (1998). El dilema del retorno: migración, género y pertenencia en un contexto transnacional. Zamora, Michoacán, México: El Colegio de Michoacán, El Colegio de Jalisco.

Galvin, Treasa M. (2015). “We Deport Them but They Keep Coming Back': The Normalcy of Deportation in the Daily Life of 'Undocumented' Zimbabwean Migrant Workers in Botswana". Journal of Ethnic and Migration Studies [en línea], 41 (4), pp. 617-634. doi: https://doi.org/10.1080/1369183X.2014.957172 (Consultado el 8 de febrero de 2020).

González de la Rocha, Mercedes y Escobar Latapí, Agustín (1990). "La ley y la migración internacional: el impacto de la Simpson-Rodino en una comunidad de los Altos de Jalisco". Estudios Sociológicos [en línea], 8 (24), pp. 517-546. Disponible en: https:// estudiossociologicos.colmex.mx/index.php/es/article/view/1132/1132 (Consultado el 20 de enero de 2020).

Goycoechea, Alba y Ramírez Gallegos, Franklin (2002). "Se fue, ¿a volver? Imaginarios, familia y redes sociales en la migración ecuatoriana a España (1997-2000)". Íconos. Revista de Ciencias Sociales, Núm. 14 [en línea], pp. 32-45. doi: https://doi.org/10.17141/ iconos.14.2002.582 (Consultado el 20 de enero de 2020).

Guarnizo, Luis Eduardo (1997). "The Emergence of a Transnational Social Formation and The Mirage of Return Migration Among Dominican Transmigrants". Identities (Identitiesglob stud) [en línea], 4 (2), pp. 281-322. Disponible en: https://www.researchgate.net/ publication/315487571 The Emergence of a Transnational Social Formation and The Mirage of Return Migration Among_Dominican Transmigrants (Consultado el 13 de octubre de 2020). 
Hannam, Kevin, Mimi Sheller y John Urry (2006). "Editorial: Mobilities, Immobilities and Moorings". Mobilities [en línea], 1 (1), pp. 1-22. doi: https://doi. org/10.1080/17450100500489189 (Consultado el 20 de enero de 2020).

Hirai, Shinji (2012). “¡Sigue los símbolos del terruño!’: etnografía multilocal y migración transnacional", en Ariza, Marina y Velasco, Laura (coords.). Métodos cualitativos y su aplicación empirica. Por los caminos de la investigación sobre migración internacional. México, D.F., México: Instituto de Investigaciones Sociales, Universidad Nacional Autónoma de México, Dirección General de Asuntos del Personal Académico, El Colegio de la Frontera Norte, pp. 77-107. Disponible en: https://www.iis.unam.mx/metodos-cualitativos-y-suaplicacion-empirica-por-los-caminos-de-la-investigacion-sobre-migracion-internacional/ (Consultado el 10 de marzo de 2021).

Hirai, Shinji (2013). "Formas de regresar al terruño en el transnacionalismo. Apuntes teóricos sobre la migración de retorno". Alteridades [en línea], 23 (45), pp. 95-105. Disponible en: https://alteridades.izt.uam.mx/index.php/Alte/article/view/718 (Consultado el 20 de enero de 2020).

Hirai, Shinji y Sandoval, Rebeca (2016). "El itinerario subjetivo como herramienta de análisis: las experiencias de los jóvenes de la generación 1.5 que retornan a México". Mexican Studies/Estudios Mexicanos [en línea], 32 (2), pp. 276-301. doi: https://doi.org/10.1525/ mex.2016.32.2.276 (Consultado el 7 de agosto de 2021).

Instituto Nacional de Geografía e Informática (INEGI) (2020). Censo de Población y Vivienda 2020. Tabulados [en línea]. Disponible en: https:/www.inegi.org.mx/programas/ ccpv/2020/default.html (Consultado el 27 de enero de 2021).

Izquierdo Escribano, Antonio (2000). "El proyecto migratorio y la integración de los extranjeros". Revista de Estudios de Juventud [en línea], Núm. 49. Disponible en: http://www.injuve.es/ sites/default/files/Revista49-3.pdf (Consultado el 14 de enero de 2019).

Jardón Hernández, Ana Elizabeth (2017). Encuesta Dinámicas de la emigración y el retorno en comunidades rurales del sur del Estado de México. Ciudad de México, México: Universidad Autónoma del Estado de México.

Jardón Hernández, Ana Elizabeth y Hernández Lara, Itzel (2019). “Dinámica contemporánea de los vínculos transnacionales. Estudio de caso de una comunidad migrante en el sur del Estado de México”. Si Somos Americanos. Revista de Estudios Transfronterizos [en línea], 19 (1), pp. 66-84. Disponible en: https://www.sisomosamericanos.cl/index. $\mathrm{php/sisomosamericanos/article/view/890} \mathrm{(Consultado} \mathrm{el} 3$ de marzo de 2020).

Jardón Hernández, Ana Elizabeth y Ronzón Hernández, Zoraida (2020). "The art of coming home. Experiencias de reinserción laboral de migrantes deportados de Estados Unidos”. Estudios Fronterizos [en línea], Vol. 21, pp. 1-23. doi: https://doi.org/10.21670/ ref.2016058 (Consultado el 10 de febrero de 2021).

King, Russell y Christou, Anastasia (2011). "Of Counter-Diaspora and Reverse Transnationalism: Return Mobilities to and from the Ancestral Homeland”. Mobilities [en línea], 6 (4), pp. 451-466. doi: https://doi.org/10.1080/17450101.2011.603941 (Consultado el 10 de marzo de 2021).

EntreDiversidades. Revista de Ciencias Sociales y Humanidades, Vol. 9, Núm. 1 (18), enero-junio 2022. Páginas: 200-222 ISSN-e: 2007-7610. https://doi.org/10.31644/ED.V9.N1.2022.A08 
Levitt, Peggy y Glick-Schiller, Nina (2004). "Conceptualizing Simultaneity: A Transnational Social Field Perspective on Society”. International Migration Review [en línea], 38 (3), pp. 1002-1039. Disponible en: https://www.jstor.org/stable/27645424?seq=1 (Consultado el 10 de marzo de 2021).

Maitilasso, Annalisa (2017). "Quiero quedarme, pero volviendo: movilidad y circulación como estrategias de re-dinamización de proyectos migratorios entre Espańa y Mali”, Huellas de la Migración [en línea], 2 (3), enero-junio, pp. 111-133. Disponible en: https:// huellasdelamigracion.uaemex.mx/article/view/4536 (Consultado el 18 de enero de 2021).

Majidi, Nassim (2020). "Assuming Reintegration, Experiencing Dislocation - Returns from Europe to Afghanistan”. International Migration (International Organization for Migration) [en línea], Vol. 59, pp. 186-201. doi: https://doi.org/10.1111/imig.12786 (Consultado el 1 de marzo de 2021).

Martínez Díaz Covarrubias, Sandra Nadezhda (2019). "Mojado en mi propia tierra”. Integración $y$ exclusión de personas migrantes de retorno en dos contextos de recepción; San Gabriel y Guadalajara (Jalisco). Tesis para obtener el grado de Doctorado en Ciencias Sociales con especialidad en Antropología Social, Centro de Investigaciones y Estudios Superiores en Antropología Social. Disponible en: https://ciesas.repositorioinstitucional.mx/ jspui/bitstream/1015/911/1/TE\%20D.C.\%202019\%20Sandra\%20N\%20Diaz\%20 Cobarrubias.pdf (Consultado el 11 de agosto de 2021).

Massey, Douglas, et al. (1991). Los ausentes. El proceso social de la migración internacional en el occidente de México. México, D.F., México: Consejo Nacional para la Cultura y las Artes, Alianza Editorial. Disponible en: http://www.catedrajorgedurand.udg.mx/sites/default/ files/los ausentes.pdf (Consultado el 10 de agosto de 2021).

Mendoza, Celia (2021). "Biden asegura a los latinos que su 'Administración siemprelos respaldará”. Voz de América [en línea], 26 de julio. Disponible en: https://www.vozdeamerica.com/ inmigracion/presidente-biden-dice-latinos-que-su-administraci\%C3\%B3n-siempre-losrespaldara (Consultado el 9 de agosto de 2021).

Mummert, Gail (2015). "Pensando las familias transnacionales desde los relatos de vida: análisis longitudinal de la convivencia intergeneracional”, en Ariza, Marina y Velasco, Laura (coords.). Métodos cualitativos y su aplicación empirica. Por los caminos de la investigación sobre migración internacional. 2a edición. México, D.F., México: Instituto de Investigaciones Sociales, Universidad Nacional Autónoma de México, Dirección General de Asuntos del Personal Académico, El Colegio de la Frontera Norte, pp. 151-184.

Papademetriou, Demetrios G. y Terrazas, Aaron (2009). Immigrants and the Current Economic Crisis: Research Evidence, Policy Challenges, and Implications [en línea]. Washington D.C., United States of America: Migration Policy Institute. Disponible en: https:// www.migrationpolicy.org/research/immigrants-and-current-economic-crisis-researchevidence-policy-challenges-and-implications (Consultado el 10 de marzo de 2021).

Parella, Sònia, et al. (2019). "Sufrimiento social y migraciones de retorno: una propuesta conceptual”. Apuntes. Revista de Ciencias Sociales [en línea], 46 (84), pp. 37-63. doi: http://dx.doi.org/10.21678/apuntes.84.1013 (Consultado el 1 de marzo de 2021).

EntreDiversidades. Revista de Ciencias Sociales y Humanidades, Vol. 9, Núm. 1 (18), enero-junio 2022. Páginas: 200-222 ISSN-e: 2007-7610. https://doi.org/10.31644/ED.V9.N1.2022.A08 
Piñeiro Aguiar, Eleder y Ferrer Muñoz, Manuel (2015). "Las inseguridades del retorno. Viajes de vuelta y las vueltas de los viajes". Barataria. Revista Castellano-Manchega de Ciencias Sociales [en línea], Núm. 19, pp 173-183. doi: https://doi.org/10.20932/barataria. v0i19.34 (Consultado el 1 de marzo de 2021).

Portes, Alejandro (2005). "Convergencias teóricas y evidencias empíricas en el estudio del transnacionalismo de los inmigrantes”. Migración y Desarrollo [en línea], 4 (1), pp. 2-19. Disponible en: https://www.redalyc.org/pdf/660/66000401.pdf (Consultado el 22 de marzo de 2021).

Pujadas, Joan J. (2000). "El método biográfico y los géneros de la memoria”. Revista de Antropología Social [en línea], Vol. 9, pp. 127-158. Disponible en: https://revistas.ucm.es/index.php/ RASO/article/view/RASO0000110127A (Consultado el 17 de febrero de 2020).

Red Unidos (2021). Twitter Storm. Vamos, juntos podemos cambiar las cosas [video]. Disponible en: https://fb.watch/5dHy EYMHw/ (Consultado el 25 de enero de 2021).

Rosaldo, Renato (2000). Cultura y verdad. La reconstrucción del análisis social. Quito, Ecuador: Ediciones Abya-Yala. Disponible en: https://digitalrepository.unm.edu/cgi/viewcontent. cgi?article $=1064 \&$ context=abya yala $($ Consultado el 11 de agosto de 2021).

Sanz Hernández, Alexia (2005). "El método biográfico en investigación social: potencialidades y limitaciones de las fuentes orales y los documentos personales". Asclepio [en línea], 57 (1), pp. 99-116. doi: https://doi.org/10.3989/asclepio.2005.v57.i1.32 (Consultado el 5 de febrero de 2018).

Sassone, Susana María (1988). "Imaginarios migratorios del retorno: lazos y lugares". Caravelle [en línea], Núm. 91, pp. 73-85. Disponible en: https://www.jstor.org/ stable/40854451?seq=1 (Consultado el 5 de febrero de 2018).

Sayad, Abdelmalek (2010). "El retorno, elemento constitutivo de la condición del inmigrante. Selección de textos". Empiria. Revista de Metodología de Ciencias Sociales [en línea], Núm. 19, pp. 263-273. Disponible en: https://www. proquest.com/openview/73af03aedfd 838 cf 2 bd 2 cf7 1 eddb915a/1.pdf?pqorigsite $=$ gscholar \&cbl=1596377 (Consultado el 10 de marzo de 2021).

Schuster, Liza y Majidi, Nassim (2013). "What Happens Post-Deportation? The Experience of Deported Afghans”. Migration Studies [en línea], 1 (2), pp. 221-240. doi: https://doi. org/10.1093/migration/mns011 (Consultado el 10 de marzo de 2021).

Sinatti, Giulia (2011). “Mobile Transmigrants' or 'Unsettled Returnees'? Myth of Return and Permanent Resettlement Among Senegalese Migrants”. Population, Space and Place, Special Issue: Return and Onward Migration [en línea], 17 (2), pp. 153-166. doi: https:// doi.org/10.1002/psp.608 (Consultado el 4 de febrero de 2020).

Torre Cantalapiedra, Eduardo (2016). "Explaining State and Local Anti-Immigrant Policies in the United States: The Case of Arizona's SB 1070”. Migraciones Internacionales [en línea], 8 (3), pp. 37-63. doi: https://doi.org/10.17428/rmi.v8i3.612 (Consultado el 6 de agosto de 2021).

EntreDiversidades. Revista de Ciencias Sociales y Humanidades, Vol. 9, Núm. 1 (18), enero-junio 2022. Páginas: 200-222 ISSN-e: 2007-7610. https://doi.org/10.31644/ED.V9.N1.2022.A08 